not evolve until the Silurian, which followed the Ordovician, this relatively complex weathering rate law is replaced by one that has a linear dependence on atmospheric $\mathrm{CO}_{2}$. Aside from being arbitrary, this approximation ignores the possible presence of widespread microbial mat cover, a phenomenon that Schwartzman and Volk have suggested ${ }^{8}$ might be very effective in drawing down atmospheric $\mathrm{CO}_{2}$.

Berner's own estimate for the uncertainty in predicted $\mathrm{CO}_{2}$ concentrations during the late Ordovician is at least a factor of 5, from 4 times to over 20 times the present level. If the lower bound of his $\mathrm{CO}_{2}$ estimates is used, along with an estimated 4 per cent reduction in solar luminosity ${ }^{4}$, the net radiative forcing of the atmosphere would be approximately the same as today ${ }^{9}$, and the paradox of the high-latitude glaciation effectively disappears. Conversely, if the upper bound on $\mathrm{CO}_{2}$ pressure is used, it is virtually impossible to produce continental glaciation using Crowley and Baum's model. Indeed, the latter problem would be further exacerbated had Berner included low solar luminosity in his own calculation. This would have lowered surface temperatures and reduced weathering rates, allowing atmospheric $\mathrm{CO}_{2}$ to climb even higher than Berner calculated.

The other half of Crowley and Baum's glacial climate theory involves the importance of continental positioning and seasonality on ice-sheet development. Their idea, which was originally developed to explain the ice-free midCretaceous $^{10}$ (around 100 million years ago) is that ice sheets are difficult to form when a large continent is positioned directly over the South Pole, because the warm summertime temperatures prevent the interannual accumulation of snow and ice. The growth of ice sheets is easiest when the continent is positioned tangential to the pole (so that the pole lies on a coastline) because the high thermal inertia of the cold polar ocean keeps the summers relatively cool. This concept is demonstrably effective in Crowley and Baum's energy-balance climate model and has a certain degree of merit on purely logical grounds. Whether the late Ordovician glaciation provides a critical test for this idea is debatable, though, as one might explain the observation using $\mathrm{CO}_{2}$ and solar luminosity alone.

What the Crowley and Baum paper really points out is the need for a $\mathrm{CO}_{2}$ palaeobarometer that extends back beyond the past two hundred thousand years. We can never hope to understand more ancient climates without some reliable means of estimating past atmospheric $\mathrm{CO}_{2}$ concentrations. Several groups, some of them mentioned by NATURE · VOL 355 - 20 FEBRUARY 1992

\section{Triple helix in a trice}

NATURE loves nothing more than a helix, and what can be done once can be tried three times over. In Angewandte Chemie (Int. Edn Engl. 30. 1490-1492; 1991) Alan F. Williams and colleagues at the University of Geneva describe the synthesis of a triple-helical complex held together by a pair of cobalt ions. The synthesis of helically coordinated organometallic complexes was pioneered in the laboratory of Jean-Marie Lehn (see Nature 346, 339342 , 314-315; 1991) who uses copper ions to lock together pairs of coiling ligands. The same philosophy is now employed by Williams and colleagues. Each ligand, a sinuous chain of aromatic rings and heterocycles (see below), has four binding sites (nitrogen atoms)

but is too inflexible to wrap entirely around a single metal centre. The cobalt ions seek octahedral coordination, and so can bind to two of the four coordination sites

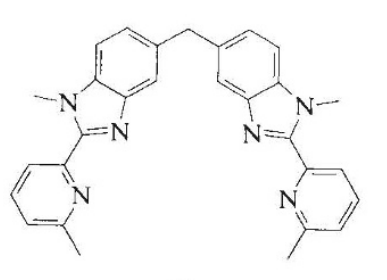

$\mathrm{L}$

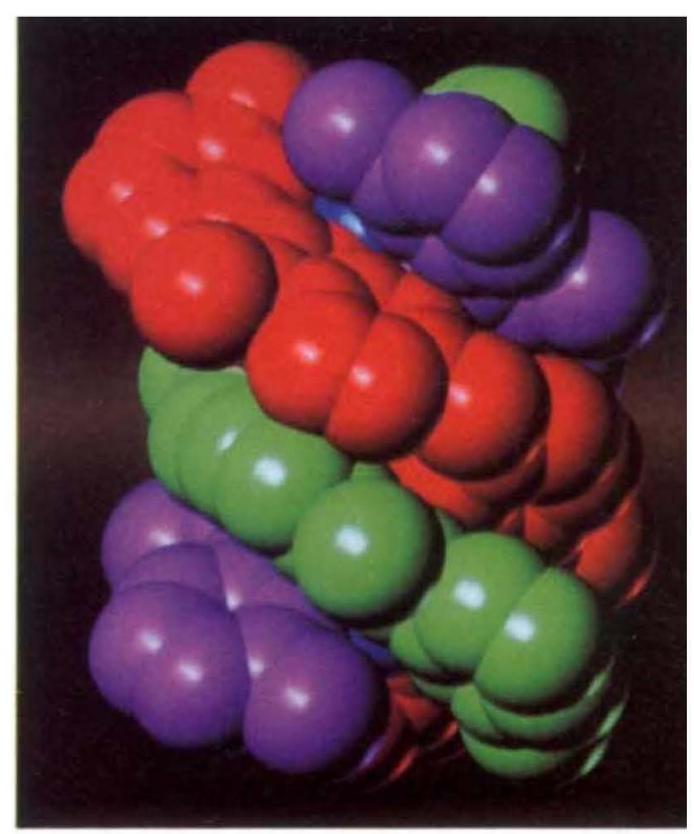
on each of three ligands. The free ends of the ligands can then latch onto a second cobalt ion. The authors found that mixing a solution of the ligand with cobalt perchlorate produced, after isolation, roseorange crystals $\mathrm{CO}_{2} \mathrm{~L}_{3}\left(\mathrm{ClO}_{4}\right)_{4}$, whose colour is typical of octahedrally coordinated cobalt. X-ray crystallography confirmed that the complex's struc-

ture is that shown in the colour-coded, space-filling model shown above, in which a (blue-coloured) cobalt ion can be seen peeking out between the ligands. As might be expected, strain in the ligand prevents the coordination of the cobalt ions from being perfectly octahedral. (Figures courtesy of Alan F. Williams.)

R.P.

Crowley and Baum, have been working on this problem using various approaches. One intriguing new idea is based on the abundance and isotope compositions of carbonates in ancient soils ${ }^{11}$ : higher soil carbonate abundances and more negative $\delta^{13} \mathrm{C}$ values should correspond to higher atmospheric $\mathrm{CO}_{2}$. (Photosynthetic organisms produce isotopically light carbon; high ambient $\mathrm{CO}_{2}$ partial pressures dilute this effect and produce isotopically heavier carbon.) A variation of this concept has recently been applied to the late Ordovician ${ }^{12}$; the inferred atmospheric $\mathrm{CO}_{2}$ level is about 16 times the present level, in remarkable agreement with Berner's model. Readers are left to judge for themselves whether this agreement is accidental.

Other than ice-core analyses, none of the proposed $\mathrm{CO}_{2}$ palaeobarometers has gained widespread acceptance, possibly because all seem to involve large uncertainties. The experience with ice cores over the past decade, however, shows that scientific disbelief will be suspended if a method produces self-consistent, reproducible results. One can only hope that one of the techniques being studied will eventually pass this test. If this happens, we will then be in a much better position to understand the intricacies of palaeoclimate.

James F. Kasting is in the Department of Geosciences, The Pennsylvania State University, University Park, Pennsylvania 16802, USA.

1. Sagan, C. \& Mullen, G. Science 177, 52-56 (1972)

2. Owen, T., Cess, R. D. \& Ramanathan, V. Nature 277 , 640-642 (1979).

. Walker, J. C. G., Hays, P. B. \& Kasting, J. F. J. geophys. Res. 86, 9776-9782 (1981).

4. Crowley, T. J. \& Baum, S. K. J. geophys. Res. 96, 22597-22610 (1991)

5. Berner, R. A. Science 249, 1382-1386 (1990)

6. Gaffin, S. Am. J. Sci. 287, 596-611 (1987).

7. Volk, T. Am. J. Sci. 287, 763-779 (1987).

8. Schwartzman, D. W. \& Volk, T. Nature 340, 457-460 (1989)

9. Kiehl, J. T. \& Dickinson, R. E. J. geophys. Res. 92, 2991-2998 (1987)

10. Crowley, T. J., Mengel, J. G. \& Short, D. A. Nature 329 803-807 (1987)

11. Cerling, T. E. Am. J. Sci. 291, 387-400 (1991)

12. Yapp, C. J. \& Poths, H. Nature 355, 342-344 (1992). 